\title{
Efeito da somatotropina na população folicular, recuperação de oócitos e produção in vitro de embriões em vacas Gir
}

\author{
Alessandra de Almeida Ramos ${ }^{1}$, Ademir de Moraes Ferreira ${ }^{2}$, Wanderlei Ferreira de Sá2, \\ João Henrique Moreira Viana ${ }^{2}$, Luiz Sérgio de Almeida Camargo ${ }^{2}$, Juliana Polisseni ${ }^{2}$, \\ Marc Henry ${ }^{3}$
}

\footnotetext{
${ }^{1}$ Empresa de Pesquisa Agropecuária de Minas Gerais, Juiz de Fora, MG.

2 Embrapa Gado de Leite, Juiz de Fora, MG.

${ }^{3}$ Universidade Federal de Minas Gerais, Belo Horizonte, MG.
}

RESUMO - Avaliou-se o efeito da pré-estimulação ovariana com somatotropina bovina recombinante (rbST), associada ou não ao FSH, sobre a população folicular, a recuperação de oócitos e a produção in vitro de embriões em vacas Gir. Utilizaram-se vacas não-lactantes, em boas condições reprodutiva e corporal, cujo ciclo estral foi sincronizado pela administração de $0,5 \mathrm{mg}$ de cloprostenol. Durante o experimento, as vacas receberam continuamente implantes auriculares de norgestomet, renovados a cada 14 dias, e, posteriormente, foram submetidas aos tratamentos: T1 ou controle - punção sem tratamento pré-estimulatório; T2 - aplicação única de $160 \mathrm{mg}$ de rbST antes de cada punção; e T3 - punção após o tratamento com $160 \mathrm{mg}$ de rbST em aplicação única, seguida de administração de 250 UI de FSH em doses decrescentes. Os oócitos foram maturados e fertilizados in vitro e os presumíveis zigotos foram cultivados por 192 horas pós-fertilização. Os tratamentos não foram diferentes quanto à população folicular presente no ovário. Entretanto, com a administração de 250 UI de FSH (T3), verificou-se aumento no diâmetro do maior folículo e no número de folículos grandes e médios e diminuição no número de folículos pequenos. A taxa de recuperação não diferiu entre o tratamento controle e T3 (com administração de FSH), mas foi menor no T2 (aplicação, em dose única, de $150 \mathrm{mg}$ de rbST antes de cada punção). O número de oócitos de grau 1 foi maior e o de degenerados, menor no T3 em relação ao T1 e ao T2. O rbST (T2) aumentou a taxa de clivagem e a produção de blastocistos e, quando associado ao FSH, melhorou a qualidade dos oócitos nos animais Gir.

Palavras-chave: bovinos, Gir, punção folicular, rbST

\section{Effect of somatotropin on follicular population, oocyte retrieval and in vitro embryo production in Gir cows}

\begin{abstract}
The aim of this study was to evaluate ovarian pre-stimulation using recombinant bovine somatotropin (rbST) or rbST associated to FSH on follicular population, oocyte retrieval and in vitro embryo production in Gir cows (Bos indicus). Estrous cycle of non-lactating cycling cows with similar body and reproductive conditions were synchronized with cloprostenol followed by norgestomet ear implants, replaced every fourteen days. The animals were randomly distributed in three treatments: TI or control (punctured without pre-stimulation), TII (injection of $160 \mathrm{mg}$ of rbST, before each aspiration) and TIII (injection of $160 \mathrm{mg}$ of rbST followed by administration of 250 U.I. of FSH, before each aspiration). Oocytes were maturated and fertilized in vitro and presumptive zygotes were cultured in vitro for 192 hours post-fertilization. Treatments did not differ for ovarian follicular population. However, an increase in the diameter of the largest follicle and in the number of large and medium follicles with reduction in the number of small follicles was observed for TIII. Oocyte recovery did not differ between TI and TIII, but recovery rate was lower for TII. The number of grade I oocytes was higher and the number of degenerated oocytes was lower for TIII than for TI or TII. The rbST increased cleavage rate and blastocyst production, and when associated to FSH the quality of oocyte in Gir animals was improved.
\end{abstract}

Key Words: bovine, Gir, ovum pick-up, rbST

\section{Introdução}

A manipulação da dinâmica folicular em bovinos pode permitir maior disponibilização de oócitos pela técnica de punção folicular guiada por ultra-som para uso em programas de produção in vitro de embriões (PIVE). Essa maior disponibilização de oócitos pode ser obtida pelo uso de somatotropina bovina recombinante ( $\mathrm{rbST})$, que tem apresentado efeito no crescimento folicular em vacas (Gong et al., 1991, 1993; De La Sota et al., 1993; Lucy et al., 1993).

A rbST aumenta a população de folículos em animais de origem européia (Gong et al., 1991, 1993, 1996, 1997; De La 
Sota et al., 1993; Webb et al., 1994; Kirby et al., 1997a,b; Bols et al., 1998) e em vacas Nelore (Carter et al., 1998; Buratini Jr. et al., 1999). Crystal et al. (1997) demonstraram que o número de folículos com diâmetro de 3 a 5 mm e de 6 a 9 mm é maior em vacas tratadas com BST em relação àquelas não tratadas e relataram que o efeito deste hormônio seria primeiramente na fase de recrutamento do crescimento folicular, não sendo afetadas a seleção de folículos grandes e a taxa de ovulação. Entretanto, Bols et al. (1998) relataram que, embora o recrutamento de folículos tenha aumentado antes da aspiração em animais tratados com rbST, o número e a qualidade dos ovócitos, assim como o número de blastocistos cultivados in vitro não foi afetado. Contudo, vários estudos têm comprovado tendência de melhor qualidade de oócitos nos animais rbST-tratados (Pavlok et al., 1996; Bevers et al., 1997; Pivato et al., 1999). Tem-se evidenciado, inclusive, que o hormônio do crescimento, o IGF-1, e as proteínas ligadoras de IGF (IGFBPs) são importantes no controle da função ovariana. O rbST promove aumento do IGF-1 no fluido folicular (Herrler et al., 1994), o que poderia melhorar a qualidade dos ovócitos e, conseqüentemente, a maturação e a formação in vitro de blastocistos. A adição de IGF-1 (Markkula \& Makarevich, 2001) ou de rbST (Izadyar et al., 1996) ao meio da maturação in vitro tem auxiliado a maturação nuclear e a capacidade de desenvolvimento dos oócitos, refletidas no aumento da formação de blastocistos. Além disso, o uso da somatotropina pode preservar os ovócitos da degeneração atrésica (Pavlok et al., 1996).

O uso da rbST antes do início das sessões de punção folicular pode ser um valioso recurso para aumentar o número e a qualidade dos oócitos coletados in vivo dos embriões produzidos in vitro em vacas Gir. Considerando que a maioria dos dados na literatura é proveniente de bovinos de origem européia e que animais europeus e indianos diferem em vários aspectos em sua fisiologia reprodutiva (Rhodes et al., 1978; Segerson et al., 1984; Rhodes et al., 1995; Figueiredo et al., 1997; Viana et al., 2000), é necessária uma avaliação da resposta dos animais Gir ao tratamento com rbST. Neste estudo, avaliou-se a utilização do tratamento com rBST, associado ou não ao FSH, antes das sessões de punção folicular como recurso para aumentar a taxa de recuperação e a qualidade dos ovócitos, bem como a PIVE, em vacas da raça Gir.

\section{Material e Métodos}

Foram utilizadas 24 vacas Gir multíparas, não-lactantes, com escore corporal entre 3 e 4 (sendo $1=$ muito magra e 5 = gorda, segundo Ferreira et al., 1999) e apresentando dois ciclos estrais normais antes do início do experimento. Os animais foram sincronizados pela administração intramuscular de 0,5 mg de cloprostenol (Ciosin, Coopers) e, durante o experimento, receberam continuamente implantes auriculares contendo $3 \mathrm{mg}$ de norgestomet (Crestar, Intevet), renovados a cada 14 dias. Posteriormente, os animais foram submetidos aos seguintes tratamentos:

T1: punção folicular sem estimulação hormonal (controle);

T2: punção folicular após tratamento com $160 \mathrm{mg}$ de rbST (Boostin ${ }^{\circledR}$, Coopers) em aplicação única quatro dias antes de cada punção;

T3: punção folicular após tratamento com $160 \mathrm{mg}$ de rbST em aplicação única quatro dias antes de cada punção, seguida de administração de 250 UI de hormônio folículo estimulante (Pluset, Serono), em seis aplicações em doses decrescentes $(75,50,50,25,25$, e 25 UI) administradas em intervalos de 12 horas nos três dias precedentes à punção.

Foram realizadas duas repetições para cada tratamento em todos os grupos (48 punções para cada tratamento).

As punções foliculares foram realizadas por um mesmo técnico utilizando-se um aparelho de ultra-sonografia equipado com transdutor setorial intravaginal de 5 / 7,5 MHZ e um dispositivo guia para punção folicular. Folículos com diâmetro superior a $3 \mathrm{~mm}$ foram identificados, mensurados e puncionados utilizando-se agulhas $19 \mathrm{G}$ e uma pressão de vácuo de $80 \mathrm{mmHg}$, correspondendo a um fluxo de $14 \mathrm{~mL}$ de água/minuto. O líquido folicular foi inicialmente recuperado em tubos plásticos de $50 \mathrm{~mL}$ (Falcon) contendo $15 \mathrm{~mL}$ de DPBS acrescido de $10 \%$ de soro fetal bovino (SFB) e $100 \mathrm{UI} / \mathrm{mL}$ de heparina (Liquemine ${ }^{\circledR}$, Roche), sendo os oócitos posteriormente separados em um filtro de coleta de embriões com malha de $80 \mu$ (Millipore). Os complexos cumulus-oócito recuperados foram transferidos para placas de cultivo contendo DPBS acrescido de $10 \%$ de SFB a $37^{\circ} \mathrm{C}$ e avaliados em um microscópio estereoscópio com aumento final de 50x, por um mesmo técnico.

Foram selecionados para o cultivo oócitos com no mínimo três camadas de células da granulosa compactas, citoplasma homogêneo ou apresentando pequenas irregularidades.

Os oócitos selecionados foram acondicionados em tubos plásticos de 1,5 mL contendo meio Talp-Hepes e mantidos em estufa a $39^{\circ} \mathrm{C}$ até o momento do transporte para o Laboratório de Embriologia. O transporte foi realizado utilizando-se uma câmara incubadora (Modular Incubator Chamber, Billups-Rothenberg) mantida a $39^{\circ} \mathrm{C}$ em uma bolsa térmica e o tempo médio de transporte foi de 40 minutos a 1 hora. 
Os oócitos foram submetidos à maturação in vitro em meio TCM-199 acrescido de $10 \%$ de soro de vaca em cio e $20 \mathrm{mg} / \mathrm{mL}$ de $\mathrm{FSH}$, por 22 horas, em estufa incubadora a $39^{\circ} \mathrm{C}$ com $5 \%$ de $\mathrm{CO}_{2}$ e $95 \%$ de umidade. Após a maturação, todos os oócitos foram fertilizados com sêmen congelado, de mesma partida, de um touro da raça Gir previamente selecionado. Para separação de espermatozóides vivos e mortos, foi utilizado o método de swim up. A fecundação in vitro foi realizada em gotas de $100 \mu \mathrm{L}$ de meio Fert-Talp acrescido de $10 \mu \mathrm{g} / \mathrm{mL}$ de heparina, cobertas com óleo mineral, com concentração espermática de 2,0 x $10^{6}$ espermatozóides/mL por um período de aproximadamente 22 horas (Parrish et al., 1986).

Os presumíveis zigotos foram co-cultivados com células da granulosa em CR2aa acrescido de $10 \%$ SBF, em gotas de $50 \mathrm{~mL}$ cobertas com óleo mineral. A avaliação da taxa de clivagem e a renovação de $50 \%$ do meio foram realizadas 72 horas pós-fecundação. A taxa de produção de blastocisto foi avaliada 192 horas pós-fecundação. Todas as etapas foram realizadas em estufa incubadora nas mesmas condições da maturação in vitro.

Os dados foram avaliados quanto ao atendimento das pressuposições da análise de variância (normalidade dos dados, aditividade, independência dos dados e constância de variância). Como a maioria das variáveis não atendeu a esses requisitos e não se obteve transformação adequada para os dados, procederam-se às análises utilizando-se testes estatísticos não-paramétricos. Assim, as características número total de folículos, diâmetro do maior folículo e número de folículos grandes ( $\geq 9 \mathrm{~mm})$, médios ( 6 a $8 \mathrm{~mm}$ ) e pequenos $(\leq 5 \mathrm{~mm})$ foram analisadas pelo teste de KruskalWallis e as taxas de recuperação, clivagem e produção de blastocistos, pelo teste do qui-quadrado.

\section{Resultados e Discussão}

O uso do rbST, associado ou não ao FSH, não aumentou $(\mathrm{P}>0,05)$ o número total de folículos submetidos à punção. $\mathrm{O}$ diâmetro do maior folículo e o número de folículos grandes, médios e pequenos também não diferiram $(\mathrm{P}>0,05)$ entre os tratamentos controle e com rbST. Entretanto, associação do rbST com o FSH resultou em aumento $(\mathrm{P}<0,05)$ no diâmetro do maior folículo em relação ao tratamento controle e no número de folículos grandes e médios, com redução $(\mathrm{P}<0,05)$ no número de folículos pequenos em relação ao tratamentos controle e com rbST (Tabela 1).

Diversos autores têm reportado que o tratamento com rbST aumenta o número de folículos ovarianos (Gong et al., 1991; 1993; De La Sota et al., 1993; Lucy et al., 1993; Webb et al., 1994; Kirby et al., 1997ab) e o número de folículos classificados como pequenos (Gong et al., 1991; 1993; Crystal et al., 1997; Bols et al., 1998; Buratini Jr. et al., 1999; Pivato et al., 1999; Buratini et al., 2000; Roth et al., 2002). Entretanto, neste estudo, o crescimento folicular aumentado não foi observado após o uso de rbST. Pavlok et al. (1996) também não obtiveram aumento no número total de folículos com a administração de uma injeção de rbST três dias antes da coleta dos ovários em matadouro. Essas diferenças podem ser atribuídas a diversos fatores, como a dosagem utilizada, a condição nutricional do animal e a diferença entre raças.

Apesar de Santl et al. (1998) não terem observado correlação positiva entre as concentrações séricas de IGF-1 e os números de folículos e oócitos em novilhas tratadas cin rbST, é geralmente aceito que o efeito do rbST no desenvolvimento dos folículos antrais seja mediado por aumentos

Tabela 1 - Número e classificação dos folículos ovarianos presentes no ovário, número total de oócitos recuperados por punção folicular e taxa de recuperação (\%) em vacas Gir não tratadas (T1), tratadas com somatotropina bovina recombinante (T2) e com somatotropina bovina recombinante associada a hormônio folículo estimulante (T3)

Table 1 - Number and classification of follicles present in ovary, total number of oocytes (mean \pm standard deviation) retrieved by ovum pick-up and recuperation rate (\%) in no-treated Gir cows (T1), treated with recombinant bovine somatotropin (T2) and recombinant bovine somatotropin associated with follicle stimulating hormone (T3)

$11,88 \pm 3,75^{\mathrm{a}}$ $9,88 \pm 3,04^{\mathrm{a}}$ $0,79 \pm 0,98^{\mathrm{a}}$ $\mathrm{n}$ ㅇ de folículos $\leq 5 \mathrm{~mm}$ (Number of follicles $\leq 5 \mathrm{~mm}$ )

Total de oócitos recuperados/seção (Total number of recuperated oocytes/section) Taxa de recuperação (Recuperation rate)
$3,46 \pm 1,77^{\mathrm{a}}$

$7,58 \pm 2,72^{\mathrm{a}}$

$7,46 \pm 5,77^{\mathrm{a}}$ $62,81^{\mathrm{a}}$
$15,83 \pm 5,94^{\mathrm{a}}$

$14,78 \pm 4,86^{\mathrm{b}}$

$6,00 \pm 3,88^{\mathrm{b}}$

$7,35 \pm 4,18^{b}$

$2,39 \pm 2,50^{\mathrm{b}}$

$9,00 \pm 5,11^{\mathrm{a}}$ $56,87^{\mathrm{b}}$

a, b Médias seguidas por letras diferentes na mesma linha diferem entre si $(P<0,05)$

Taxa de recuperação $=\left(\right.$ total de oócitos recuperados por tratamento/total de folículos por tratamento ${ }^{\star} 100$

$a, b$ Means followed by different letters in the same row are statistically different $(P<0.05)$

Recuperation rate $=\left(\right.$ total number of retrieved oocyte in treatment/ total number of follicles in treatment) ${ }^{*} 100$. 
nas concentrações séricas de IGF-1 e/ou insulina (Kirby et al., 1997a,b; Buratini Jr. et al., 2000; Lucy, 2000; Cushman et al., 2001; Roth et al., 2002). Sugere-se que somente doses de rbST capazes de promover aumento nas concentrações de IGF-1 aumentem o número de folículos pequenos (Gong et al., 1993; 1997). A dose utilizada neste experimento pode não ter sido suficiente para alterar o desenvolvimento folicular, o que não foi verificado, pois não foi possível avaliar as concentrações de IGF-1 neste experimento. Além disso, animais indianos parecem ter menor resposta ovariana que os europeus a uma mesma concentração de IGF-1 induzida pelo rbST (Buratini Jr. et al., 2000). Há relatos de que o sistema IGF ovariano pode diferir entre animais Bos indicus e Bos taurus. Vacas Brahman, comparadas a vacas Angus (Simpson et al., 1994), têm maior atividade plasmática de IGFBPs. Portanto, é possível que a proporção livre e ligada de IGF-1 possa diferir entre a raça Gir e as demais raças européias.

Os efeitos da somatotropina sobre a função ovariana estão relacionados ao padrão de aporte e utilização de nutrientes por estes tecidos (Pinto Andrade et al., 1996). O tratamento com rbST exógeno estimula as concentrações séricas de IGF-1 e IGFBP-3, reduzindo a de IGFBP-2. Diminuição no consumo de alimentos pode reduzir a magnitude dessas respostas (Rausch et al., 2002). As concentrações séricas de somatotropina e o IGF mudam em resposta à condição nutricional, sendo observados aumentos na somatotropina e menores concentrações de IGF durante o balanço energético negativo, enquanto o inverso ocorre durante o balanço energético positivo (Lucy, 2000). Neste estudo, os animais foram mantidos exclusivamente a pasto e não receberam qualquer suplementação volumosa ou energética durante todo o período experimental, o que pode não ter sido suficiente para atender à demanda nutricional, o que não foi avaliado, visto que os animais apresentavam boa condição corporal e não estavam em lactação.

A somatotropina possui ação metabólica ao alterar o catabolismo dos carboidratos e das gorduras, reduzindo a utilização da glicose (Peel \& Bauman, 1987) e aumentando a glicemia. Com a redução na utilização da glicose nos tecidos periféricos, outra fonte energética deve estar disponível para manutenção dos processos fisiológicos. Neste caso, a somatotropina aumenta a mobilização de ácidos graxos (lipólise) presentes no tecido adiposo, fornecendo uma via energética alternativa (Pamela \& Harvey, 1997).

O número total de oócitos recuperados por punção não diferiu $(\mathrm{P}>0,05)$ entre os tratamentos. A utilização de hormônios promoveu diminuição $(\mathrm{P}<0,05)$ na taxa de recuperação, mas não alterou o número de oócitos obtidos por punção em relação aos animais não tratados (Tabela 1). O uso do rbST antes das punções foliculares não tem melhorado a taxa de recuperação em bovinos (Bols et al., 1998; Pivato et al., 1999; Tripp et al., 2000). Acredita-se que o rbST pode alterar a morfologia da parede folicular ou do complexo cumulus-oócito, direta ou indiretamente, pela ação do IGF-1, resultando em impedimento da recuperação do oócito (Tripp et al., 2000). O rbST tem mostrado expandir as células do cumulus in vitro (Izadyar et al., 1996), o que pode ter contribuído para a retenção do oócito no folículo aspirado. A associação do rbST ao FSH (T3) pode ter evitado esse efeito da somatotropina por ter aumentado o número de folículos grandes e médios (Tabela 1), amenizando a retenção do oócito, ocasionada, possivelmente, por alterações nas células do cumulus.

O rbST também não melhorou a qualidade morfológica dos complexos cumulus-oócito recuperados, pois não aumentou $(\mathrm{P}>0,05)$ a porcentagem de oócitos classificados como viáveis (grau 1 e 2). Outros autores também não evidenciaram melhora na qualidade dos oócitos ao utilizarem rbST antes das sessões de punção folicular (Bols et al., 1998; Tripp et al., 2000). Entretanto, a associação ao FSH (T3) aumentou $(\mathrm{P}<0,05)$ a porcentagem de complexos cumulus-oócito de grau 1 e diminuiu $(\mathrm{P}<0,05)$ a de oócitos degenerados (Tabela 2). O FSH pode ter melhorado a qualidade morfológica dos oócitos por diminuir a população de folículos atrésicos e aumentar o diâmetro folicular, permitindo que os complexos cumulus-oócito fossem recuperados com a estrutura mais íntegra.

A somatotropina pareceu melhorar o desenvolvimento dos oócitos, pois aumentou as taxas de clivagem $(\mathrm{P}<0,05)$ e de produção de blastocistos $(\mathrm{P}<0,01)$, quando utilizada sozinha, e melhorou o desenvolvimento embrionário ( $\mathrm{P}=0,064)$, quando associada ao FSH (Tabela 3 ). Kuehner et al. (1993) e Gong et al. (1996) também relataram que o tratamento com rbST melhorou o desenvolvimento dos oócitos e a qualidade de embriões bovinos. $\mathrm{O}$ efeito benéfico do rbST no desenvolvimento embrionário pode estar relacionado a influências diretas ou indiretas no microambiente folicular e/ou no próprio oócito. Uma das mudanças obtidas com a administração de rbST é o aumento das concentrações intrafoliculares de IGF-1 (Roth et al., 2002), o que poderia resultar em aumento da eficiência do desenvolvimento embrionário in vitro.

Receptores de somatotropina e IGF-1 têm sido encontrados em oócitos bovinos imaturos e nas células da granulosa e do cumulus (Spicer et al., 1994; Spicer \& Stewart, 1996; Izadyar et al., 1997; Kölle et al., 1998; Yoshida et al., 1998; Lonergan et al., 2000). A adição de rbST (Izadyar et al., 1997, 1998) ou IGF-1 (Herrler et al., 1992; Markkula \& Makarevich, 2001) ao meio de maturação in vitro tem 
Tabela 2 - Classificação dos oócitos recuperados em vacas Gir não tratadas (T1) e tratadas com rbST (T2) ou com rbST em associação ao FSH (T3)

Table 2 - Classification of retrieved oocytes from no-treated Gir cows (T1), treated with recombinant bovine somatotropin (T2) and recombinant bovine somatotropin associated with follicle stimulating hormone (T3)

\begin{tabular}{|c|c|c|c|c|c|c|}
\hline \multirow{2}{*}{$\begin{array}{l}\text { Classificação dos oócitos } \\
\text { Oocyte classification }\end{array}$} & \multicolumn{2}{|c|}{$\mathrm{T} 1$} & \multicolumn{2}{|c|}{$\mathrm{T} 2$} & \multicolumn{2}{|c|}{ T3 } \\
\hline & $\mathrm{n}$ & $\%$ & $\mathrm{n}$ & $\%$ & $\mathrm{n}$ & $\%$ \\
\hline Grau 1 (Grade 1) & 37 & $20,67^{\mathrm{a}}$ & 37 & $22,16^{\mathrm{a}}$ & 67 & $32,37^{\mathrm{b}}$ \\
\hline Grau 2 (Grade 2) & 92 & $51,40^{\mathrm{a}}$ & 94 & $56,29^{\mathrm{a}}$ & 118 & $57,00^{\mathrm{a}}$ \\
\hline Parcialmente desnudados (Partially denudated) & 10 & $6,15^{\mathrm{a}}$ & 9 & $5,39^{\mathrm{a}}$ & 8 & $4,02^{\mathrm{a}}$ \\
\hline Desnudados e/ou degenerados (Denuded and/or degenerated) & 32 & $17,88^{\mathrm{a}}$ & 24 & $14,37^{\mathrm{a}}$ & 10 & $4,83^{\mathrm{b}}$ \\
\hline Expandidos (Expanded) & 8 & $4,47^{\mathrm{a}}$ & 3 & $1,80^{\mathrm{a}}$ & 4 & $1,93^{\mathrm{a}}$ \\
\hline Zona pelúcida (Zona pellucida) & 0 & $0,00^{\mathrm{a}}$ & 0 & $0,00^{\mathrm{a}}$ & 0 & $0,00^{\mathrm{a}}$ \\
\hline Total & 179 & & 167 & & 207 & \\
\hline
\end{tabular}

a, b Médias seguidas de letras diferentes na mesma linha diferem entre si $(P<0,05)$.

a, b Means followed by different letters in the same row are statistically different $(P<0.05)$

Tabela 3 - Taxas de clivagem e produção de blastocistos de oócitos recuperadosin vivoem vacas Gir não tratadas (T1), tratadas com rbST (T2) ou com rbST em associação ao FSH (T3)

Table 3 - Cleavage and blastocyst rates in no-treated Gir cows (T1), treated with recombinant bovine somatotropin (T2) and recombinant bovine somatotropin associated with follicle stimulating hormone (T3)

\begin{tabular}{|c|c|c|c|c|c|c|}
\hline \multirow{2}{*}{$\begin{array}{l}\text { Classificação dos oócitos } \\
\text { Oocyte classification }\end{array}$} & \multicolumn{2}{|c|}{$\mathrm{T} 1$} & \multicolumn{2}{|c|}{$\mathrm{T} 2$} & \multicolumn{2}{|c|}{ T3 } \\
\hline & $\mathrm{n}$ & $\%$ & $\mathrm{n}$ & $\%$ & $\mathrm{n}$ & $\%$ \\
\hline Taxa de clivagem (Cleavage rate) & 77 & $46,11^{\mathrm{a}}$ & 78 & $60,47^{\mathrm{b}}$ & 74 & $50,34^{\mathrm{ab}}$ \\
\hline Taxa de produção de blastocisto (Blastocyst production rate) & 13 & $7,78^{\mathrm{a}}$ & 25 & $19,38^{\mathrm{b}}$ & 21 & $14,29^{\mathrm{ab}}$ \\
\hline Total de oócitos cultivados (Total number of cultivated oocytes) & 167 & & 129 & & 147 & \\
\hline
\end{tabular}

a, b Médias seguidas de letras diferentes na mesma linha diferem entre si $(P<0,05)$.

a, b Means followed by different letters in the same row are statistically different $(P<0.05)$.

aumentado o número de mórulas e de blastocistos. É possível que o rbST melhore a maturação nuclear e citoplasmática dos oócitos (Bevers et al., 1997; Izadyar et al., 1997, Bevers \&Izadyar, 2002). Além disso, o tratamento das doadoras de embriões com rbST reduz a proporção de oócitos não-fecundados e aumenta o número de embriões transferíveis (Thatcher et al., 2001).

Outros autores, entretanto, não obtiveram aumento nas taxas de clivagem e produção de blastocistos após a utilização de rbST ou IGF-1 in vitro ou com rbST in vivo (Bols et al., 1998; Rieger et al., 1998; Pivato et al., 1999; Tripp et al., 2000). A utilização de diferentes sistemas de cultivo in vitro e diferenças nas doses de rbST usadas in vivo e in vitro e de oócitos provenientes de animais de raças diferentes podem ser as causas dos resultados divergentes.

\section{Conclusões}

O rbST alterou a dinâmica folicular e a qualidade dos oócitos em vacas Gir somente quando associado ao FSH.
O uso do rbST antes das punções foliculares melhorou as taxas de clivagem e produção de blastocisto in vitro em animais da raça Gir.

\section{Literatura Citada}

BEVERS, M.M.; IZADYAR, F. Role of growth hormone and growth hormone receptors in oocyte maturation. Molecular and Cellular Endocrinology, v.197, p.173-179, 2002.

BEVERS, M.M.; DIELEMAN, S.J.; HURK, V.D.R. et al. Regulation and modulation of oocyte maturation in bovine Theriogenology, v.47, p.13-22, 1997.

BOLS, P.E.J.; YSEBAET, M.T.; LEIN, A. et al. Effect of longterm treatment with bovine somatotropin on follicular dynamics and subsequent oocyte and blastocyst yield in OPU-IVF program. Theriogenology, v.49, p.983-995, 1998.

BURATINI JR., J.; PRICE, C.A.; VISINTIN, J.A. et al. Effects of dominant follicle aspiration and treatment with recombinant bovine somatotropin (bST) on ovarian follicular development in Nelore (Bos indicus) heifers. Theriogenolgy, v.54, p.421-431, 2000.

BURATINI Jr., J.; PRICE, C.A.; BÓ, G.A. et al. Os efeitos do bST e da ablação do folículo dominante sobre o desenvolvimento folicular. Arquivos da Faculdade de Veterinária UFRGS, v.27, p.147-170, 1999.

CARTER, J.A.; PARANAGUÁ, H.N.; PARANAGUÁ, H.F.N. et al. The effect of rbST on follicle populations of Nelore heifers 
during the dry season in Brazil. Theriogenology, v.49, p.342, 1998.

CRYSTAL, J.K.; SMITH, M.F.; KEISLER, D.H. et al. Follicular function in lactating dairy cows treated with sustained-release bovine somatotropin. Journal of Dairy Science, v.80, p.273-285, 1997.

CUSHMAN, R.A.; DESOUZA, J.C.; HEDGPETH, V.S. et al. Alteration of activation, growth and atresia of bovine preantral follicles by long-term treatment of cows with estradiol and recombinant bovine somatotropin. Biology of Reproduction, v.65, p.581-586, 2001.

De LA SOTA, R.L.; LUCY, M.C.; STAMPLES, C.R. et al. Effects of recombinant bovine somatotropin (sometribove) on ovarian function in lactating and nonlactating dairy cows. Journal of Dairy Science, v.76, p.1002-1013, 1993.

FERREIRA, A.M.; TORRES, C.A.A.; SILVA, J.F.C. Peso para a recuperação da atividade ovariana luteal cíclica em vacas leiteiras mestiças em anestro. Pesquisa Agropecuária Brasileira, v.34, p.481-485, 1999.

FIGUEIREDO, R.A.; BARROS, C.M.; PINHEIRO, O.L. et al. Ovarian follicular dynamics in Nelore breed (Bos indicus) cattle. Theriogenology, v.47, p.1489-1505, 1997.

GLUCKMAN, P.D.; BRAIER, B.H.; DAVIS, S.R. Physiology of somatotropic axis with particular reference to ruminant. Journal of Dairy Science, v.70, p.442-466, 1987.

GONG, J.G.; BAXTER, G.; BRAMLEY, T.A. et al. Enhancement of ovarian follicle development in heifers by treatment with recombinant bovine somatotropin: a dose-response study. Journal of Reproduction and Fertility, v.110, p.91-97, 1997.

GONG, J.G.; BRAMLEY, T.A.; WILMUT, I. et al. Pretreatment with recombinant bovine somatotropin enhances the superovulatory responses to FSH in heifers. Theriogenology, v.45, p.611-622, 1996.

GONG, J.G.; BRAMLEY, T.A.; WEBB, R. The effect of recombinant bovine somatotropin on ovarian follicular growth and development in heifers. Journal of Reproduction and Fertility, v.97, p.247-254, 1993.

GONG, J.G.; BRAMLEY, T.A.; WEBB, R. The effect of recombinant bovine somatotropin on ovarian function in heifers: follicular populations and peripheral hormones. Biology of Reproduction, v.45, p.941-949, 1991.

HERRLER, A.; EINSPANIER, R.; SCHAMS, D. et al. Effects of recombinant bovine somatotropin follicular IGF-I contents and the ovarian response following superovulatory treatment in dairy cows: a preliminary study. Theriogenology, v.41, p.601-611, 1994.

HERRLER, A.; HAHN, L.; NIEMANN, H. Effects of insulin-like growth factor-I on in vitro production of bovine embryos. Theriogenology, v.37, p.1213-1224, 1992.

IZADYAR, F.; HAGE, W.G.; COLENBRANDER, B. et al. The promotory effect of growth hormone on the developmental competence of in vitro matured bovine oocytes is due to improved cytoplasmic maturation. Molecular Reproduction and Development, v.49, p.444-453, 1998.

IZADYAR, F.; VANTOL, H.T.A.; COLENBRANDER, B. et al. Stimulatory effect of growth hormone on in vitro maturation of bovine oocytes is exerted through cumulus cells and not mediated by IGF-I. Molecular Reproduction and Development, v.47, p.175-180, 1997.

IZADYAR, F.; COLENBRANDER, B.; BEVERS, M.M. In vitro maturation of bovine oocytes in presence of growth hormone accelerates nuclear maturation and promotes subsequent embryonic development. Molecular Reproduction and Development, v.45, p.372-377, 1996

KIRBY, C.J.; SMITH, M.F.; KEISLER, D.H. et al. Follicular function in lactating dairy cows treated with sustained-release bovine somatotropin. Journal of Dairy Science, v.80, p.273-285, $1997 \mathrm{a}$
KIRBY, C.J.; WILSON, S.J.; LUCY, M.C. Response of dairy cows treated with somatotropin to a luteolytic dose of prostaglandin $\mathrm{F}_{2}$ alfa. Journal of Dairy Science, v.80, p.286-294, 1997b.

KÖLLE, S.; SINOWATZ, F.; BOIE, F. et al. Developmental changes in the expression of the growth hormone receptor messenger ribonucleic acid and protein in bovine ovary. Biology of Reproduction, v.59, p.836-842, 1998.

KUEHNER, L.F.; RIEGER, D.; WALTON, J. S. et al. The effects of a depot injection of recombinant bovine somatotropin on follicular development and embryo yield in superovulated Holstein heifers. Theriogenology, v.40, p.1003-1013, 1993.

LONERGAN, P.; GUTIERREZ-ADAN, A.; PINTADO, B. et al. Relationship between time of first cleavage and the expression of IGF-I growth factor, its receptor, and two housekeeping genes in bovine two-cell embryos and blastocysts produced in vitro. Molecular, Reproduction and Development, v.57, p.146-152, 2000.

LUCY, M.C. Regulation of ovarian follicular growth by somatotropin and insulin-like gowth factors in cattle. Journal of Dairy Science, v.83, p. 1635-1647, 2000.

LUCY, M.C.; De LA SOTA, R.L.; STAMPLES, C.R. et al. Ovarian follicular populations in lactating dairy cows treated with recombinant bovine somatotropin (sometribove) or saline and fed diets differing in fat content and energy. Journal of Dairy Science, v.76, p.1014-1027, 1993.

MARKKULA, M.; MAKAREVICH, A. Insulin-like growth factor I increases the ratio of proliferating cell nuclear antigen positive cells of in vitro produced bovine embryos. Theriogenology, v. 55, p. 432,2001

PAMELA, C.C.; HARVEY, R.A. Bioquímica ilustrada. 2.ed. Porto Alegre: Artes Médicas: 1997. 446p.

PARRISH, J.J.; SUSKO-PARRISH, J.L.; LEIBFRIED-RUTLEDGE, M.L. et al. Bovine in vitro fertilization with frozen-thawed semen. Theriogenology, v.25, p.591-600, 1986.

PAVLOK, A.; KOUTECKÁ, L.; KREJCÍ, P. et al. Effect of recombinant bovine somatotropin on follicular growth and quality of oocytes in cattle. Animal Reproduction Science, v.41, p.183-192, 1996.

PEEL, C.J.; BAUMAN, D.E. Somatotropin and lactation. Journal of Dairy Science, v.70, p.474-486, 1987.

PINTO ANDRADE, L.; RHIND, S.M.; WRIGHT, I.A. et al. Effects of bovine somatotropin (bST) on ovarian function in postpartum beef cows. Reproduction, Fertility and Development, v.8, p.951-960, 1996.

PIVATO, I.; PEREIRA, D.C.; PEIXER, M.A.S. et al. Efeito do bST sobre a taxa de recuperação e qualidade dos oócitos em bovinos. Arquivos da Faculdade de Veterinária UFRGS, v.27, p.171-186, 1999.

RAUSCH, M.I.; TRIPP, M.W.; GOVONI, K.E. et al. The influence of level of feeding on growth and serum insulin-like growth factor-I and insulin-like growth factor-I binding proteins in growing beef cattle supplemented with somatotropin. Journal of Animal Science, v.80, n.1, p.94-100, 2002.

RHODES, F.M.; DE'ATH, G.; ENTWISTLE, K.W. Animal and temporal effects on ovarian follicular dynamics in Brahman heifers. Animal Reproduction Science, v.38, p.265-277, 1995.

RHODES, R.C.; RANDEL, R.D.; HARMS, P.G. Reproductive studies of Brahman cattle. IV. Luteinizing hormone levels in ovariectomized Brahman, Brahman $\mathrm{x}$ Hereford and Hereford cows following $20 \mathrm{mg}$ dose of estradiol $-17 \beta$. Theriogenology v.10, p.429-437, 1978

RIEGER, D.; LUCIANO, A.M.; MODINA, S. et al. The effects of epidermal growth factor and insulin-like growth factor-I on metabolic activity, nuclear maturation and subsequent development of cattle oocytes in vitro. Journal of Reproduction and Fertility, v.112, p.123-130, 1998. 
ROTH, Z.; ARAV, A.; BRAW-TAL, R. et al. Effect of treatment with follicle-stimulating hormone or bovine somatotropin on the quality of oocyte aspirated in the autumn from previously heat-stressed cows. Journal of Dairy Science, v.85, p.1398-1405, 2002.

SANTL, B.; SAUERWEIN, H.; DAXEMBERGER, A. et al. Oocyte collection in cattle: is there a correlation between yield of oocyte and serum insulin-like growth factor-I levels? Theriogenology, v.49, p.403, 1998.

SEGERSON, E.C.; HANSEN, T.R.; LIBBY, D.W. et al. Ovarian and uterine morphology and function in Angus and Brahman cows. Journal of Animal Science, v.59, p.1026-1046, 1984.

SIMPSON, R.B.; CHASE JR., C.C.; SPICER, L.J. et al. Effects of exogenous insulin on plasma and follicular insulin-like growth factor-I, insulin-like growth factor binding protein activity, follicular oestradiol and progesterone, and follicular growth in superovulated Angus and Brahman cows. Journal of Reproduction and Fertility, v.102, p.483-492, 1994.

SPICER, L.J.; ALPIZAR, E.; VERNON, R.K. Insulin-like growth factor-I receptors in ovarian granulosa cells: effect of follicle size and hormones. Molecular and Cellular Endocrinology, v.102, p.69-76, 1994.

SPICER, L.J.; STEWART, R.E. Interaction among basic fibroblast growth factor, epidermal growth factor insulin and insulin-like growth factor-I (IGF-I) on cell numbers and steroidogenesis of bovine thecal cells: role of IGF-I receptors. Biology of Reproduction, v.54, p.255-263, 1996.
THATCHER, W.W.; MOREIRA, F.; SANTOS, J.E. et al. Effects of hormonal treatments on reproductive performance and embryo production. Theriogenology, v.55, p.75-89, 2001.

TRIPP. M.W.; JU, J.C.; HOAGLAND, T.A. et al. Influence of somatotropin and nutrition on bovine oocyte retrieval and in vitro development. Theriogenology, v.53, p.1581-1590, 2000.

VIANA, J.H.M.; FERREIRA, A.M.; SÁ, W.F. et al. Follicular dynamics in zebu cattle. Pesquisa Agropecuária Brasileira, v.35, n.12, p.2501-2509, 2000.

WEBB, R.; GONG, J.G.; BRAMLEY, T.A. Role of growth hormone and intrafollicular peptides in the control of follicle development in cattle. Theriogenology, v.41, p.25-30, 1994.

YOSHIDA, Y.; MIYAMURA, M.; HAMANO, S. et al. Expression of growth factor ligand and their receptor mRNAs in bovine ova during in vitro maturation and after fertilization in vitro. Journal of Veterinary Medicine, v.60, p.549-554, 1998. 